\title{
Association Between Proxy-or Self-Reported Cognitive Decline and Cognitive Performance in Memory Clinic Visitors
}

Citation for published version (APA):

Gruters, A. A. A., Ramakers, I. H. G. B., Verhey, F. R. J., Köhler, S., Kessels, R. P. C., \& de Vugt, M. E. (2019). Association Between Proxy-or Self-Reported Cognitive Decline and Cognitive Performance in Memory Clinic Visitors. Journal of Alzheimer's Disease, 70(4), 1225-1239. https://doi.org/10.3233/JAD180857

Document status and date:

Published: 01/01/2019

DOI:

10.3233/JAD-180857

Document Version:

Publisher's PDF, also known as Version of record

Document license:

Taverne

Please check the document version of this publication:

- A submitted manuscript is the version of the article upon submission and before peer-review. There can be important differences between the submitted version and the official published version of record.

People interested in the research are advised to contact the author for the final version of the publication, or visit the DOI to the publisher's website.

- The final author version and the galley proof are versions of the publication after peer review.

- The final published version features the final layout of the paper including the volume, issue and page numbers.

Link to publication

\footnotetext{
General rights rights.

- You may freely distribute the URL identifying the publication in the public portal. please follow below link for the End User Agreement:

www.umlib.nl/taverne-license

Take down policy

If you believe that this document breaches copyright please contact us at:

repository@maastrichtuniversity.nl

providing details and we will investigate your claim.
}

Copyright and moral rights for the publications made accessible in the public portal are retained by the authors and/or other copyright owners and it is a condition of accessing publications that users recognise and abide by the legal requirements associated with these

- Users may download and print one copy of any publication from the public portal for the purpose of private study or research.

- You may not further distribute the material or use it for any profit-making activity or commercial gain

If the publication is distributed under the terms of Article $25 \mathrm{fa}$ of the Dutch Copyright Act, indicated by the "Taverne" license above, 


\title{
Association Between Proxy- or Self-Reported Cognitive Decline and Cognitive Performance in Memory Clinic Visitors
}

\author{
Angélique A.A. Gruters ${ }^{\text {a }}$, Inez H.G.B. Ramakers ${ }^{\mathrm{a}, *}$, Frans R.J. Verhey ${ }^{\mathrm{a}}$, Sebastian Köhler ${ }^{\mathrm{a}}$, \\ Roy P.C. Kessels ${ }^{\mathrm{b}, \mathrm{c}}$ and Marjolein E. de Vugt ${ }^{\mathrm{a}}$ \\ ${ }^{a}$ Department of Psychiatry and Neuropsychology, School for Mental Health and Neuroscience, Alzheimer Center \\ Limburg, Maastricht University, Maastricht, The Netherlands \\ ${ }^{\mathrm{b}}$ Donders Institute for Brain, Cognition and Behaviour, Radboud University, Nijmegen, The Netherlands \\ ${ }^{\mathrm{c}}$ Department of Medical Psychology \& Radboudumc Alzheimer Center, Radboud University Medical Center, \\ Nijmegen, The Netherlands
}

Handling Associate Editor: Katherine Gifford

Accepted 11 June 2019

\begin{abstract}
.
Background: It is uncertain whether self- and proxy-reported cognitive decline in older adults reflect an actual objective cognitive dysfunction in the clinical sense, and if these are predictive for developing dementia.

Objective: The aim of the present study is to investigate the cross-sectional and longitudinal relation between subjective cognitive decline and objective cognitive performance, depressive symptoms, and to determine the predictive value for development of dementia.

Methods: We included 405 patients without dementia at first visit from the Maastricht memory clinic participating in a longitudinal cohort study. Subjective cognitive decline was measured using a self- and proxy-report questionnaire. All patients underwent a standardized neuropsychological assessment. Follow-up assessments were performed yearly for three consecutive years, and once after five years.

Results: Subjective cognitive decline was associated with lower cognitive performance and more depressive symptoms. When comparing self- $(n=342,84 \%)$ and proxy-reported decline $(n=110,27 \%)$, it was shown that proxy reports were associated with a more widespread pattern of lower cognitive performance. In participants without cognitive impairment proxy-reported decline was not associated with depressive symptoms. In contrast, self-reported decline was associated with a stable course of depressive symptoms at follow-up. Proxy-reported cognitive decline $(\mathrm{HR}=1.76,95 \% \mathrm{CI}=1.12-2.78)$, and mutual complaints ( $\mathrm{HR}=1.73, \mathrm{CI}: 1.09-2.76)$ predicted incident dementia while self-reported decline did not reach statistical significance $(\mathrm{HR}=1.26,95 \% \mathrm{CI}=0.65-2.43)$.

Conclusion: Proxy-reported cognitive decline was consistently associated with lower cognitive performance and conversion to dementia over 5 years. Self-reported cognitive decline in patients without cognitive impairment might indicate underlying depressive symptoms and thus deserve clinical attention as well.
\end{abstract}

Keywords: Cognition, dementia, depressive symptoms, mild cognitive impairment, proxy-report, subjective cognitive decline

\footnotetext{
${ }^{*}$ Correspondence to: Inez Ramakers, PhD, Alzheimer Center Limburg, Dr. Tanslaan 12, 6299 ET Maastricht, The Netherlands.
} Tel.: +31 43388 1025; E-mail: i.ramakers@maastrichtuniver
sity.nl. 


\section{INTRODUCTION}

Subjective cognitive decline is defined as selfperceived worsening of cognition over time, which is common in older adults [1]. It is often a reason for concern, resulting in visits to healthcare facilities, such as memory clinics. There is increasing evidence that the experience of cognitive decline is related to a greater risk of conversion to mild cognitive impairment (MCI) and Alzheimer's disease (AD) dementia [2-4]. A meta-analysis shows that elderly people experiencing cognitive decline are twice as likely to develop dementia [3]. However, previous studies have generated inconsistent findings with regard to the relation with objective cognitive performance and risk of conversion to dementia $[2,5,6]$. Some studies have shown that subjective cognitive decline reflects worse objective cognitive performance both at baseline and over time [7-10], whereas other studies found no associations with cognition [11-14]. On the other hand, cognitive complaints have also been shown to be closely associated with personality traits, depressive symptoms, and other psychiatric conditions [2, 11-14]. Differences in study design might explain this heterogeneity, as studies that found an association between subjective cognitive decline and objective cognitive performance have generally adopted a longitudinal and community-based design in a cognitively healthy sample while studies focusing on a memory-clinic population have not always demonstrated differences in cognitive performance $[15,16]$.

The differential prognostic value of self- as compared with proxy-reported cognitive decline is another unresolved issue. Indeed, some studies indicate that proxy-reported decline has a higher accuracy of indicating subsequent objective cognitive performance and predict future cognitive decline in comparison to self-reported decline [17, 18]. Proxyreported decline has also been shown to differentiate normal aging from future conversion to dementia, while self-reported decline did not $[19,20]$. In contrast, other studies found weak associations between proxy-reported decline and cognitive test performances [14, 21]. These discrepancies could be explained by methodological differences, variability in terminology, and a focus on subjective memory complaints and not on other cognitive domains, such as attention. Consequently, the clinical significance and prognostic value of self- and proxy-reported cognitive decline remain unclear. More insight into subjective cognitive decline might allow for identification of an at-risk population for developing $\mathrm{AD}$ dementia that is easily implemented in clinical practice. It would also facilitate the implementation of early interventions [2]. This study will extend evidence from predominantly cognitively healthy subjects to a clinical population of memory clinic visitors who actively sought help using a large memory-clinic cohort and a long follow-up period. In addition, we will explicitly focus on contrasting proxy- and self-reported cognitive decline, which includes reports of both memory and attention complaints and is based on a standardized instrument asking for the decline compared to one year prior to the assessment. To our knowledge, only a few studies have studied this in memory-clinic visitors, usually focusing on current subjective complaints. Our primary aim is to investigate the cross-sectional and longitudinal association between self- and proxy-reported cognitive decline and objective cognitive performances in nondemented memory clinic visitors. The secondary aim is to determine the association with conversion to dementia in patients with and without self- and proxyreported cognitive decline at baseline. The third aim is to investigate the cross-sectional and longitudinal association between self- and proxy-reported cognitive decline and depressive symptoms, and to repeat this analysis separately in patients with and without cognitive impairment.

\section{MATERIALS AND METHODS}

\section{Study design and participant selection}

Participants were selected from the Bio-Bank Alzheimer Center Limburg (BBACL) study, which is an ongoing prospective cohort study of patients referred to the memory clinic of the Maastricht University Medical Center in the Netherlands for an evaluation of their cognitive complaints. Patients were included if they were 55 years or older, had no cognitive impairment (NCI), or mild cognitive impairment (MCI) in the absence of dementia. Participants were classified as having MCI when they had an objectified impairment on one or more cognitive tests [22], had a Clinical Dementia Rating (CDR) score of $\leq 0.5$, and no significant interference in daily life. Performance on a cognitive test was considered impaired if the score was more than 1.5 Standard Deviation (SD) below the age-, sex, and education-adjusted normative mean [23-25]. Participants were excluded if they had dementia at 
baseline, and medical disorders, which could result in cognitive impairment. This includes Normal Pressure Hydrocephalus, Huntington's disease, recent cerebrovascular disorders (Transient Ischemic Attack [TIA] or stroke $<2$ years prior to the assessment or cognitive decline within 3 months after a TIA or stroke), brain tumor, epilepsy or encephalitis. Participants were also excluded if they had a history $(<12$ months) of or current treatment for major depressive disorder, bipolar disorder, or psychotic disorder based on DSM-IV-TR criteria. Cognitive problems as a result of excessive use of alcohol (clinician judgement) and the expectation that the participant would not reach the first-year follow-up also led to exclusion. For the present study, we selected participants who completed the self- and proxy questionnaires on cognitive decline. This resulted in a sample size of $\mathrm{N}=405$ at baseline. Figure 1 shows the flow chart of this study. Ethical approval was given by the Medical Ethics Review Committee of Maastricht University Medical Center. Participants gave written informed consent.

\section{Baseline assessment}

Standard clinical assessment as part of the diagnostic procedure at baseline included a detailed medical history of the patient, demographic information, neurological, psychiatric, and physical examinations. Furthermore, a standardized interview based on the Disability Assessment for Dementia Scale (DAD) [26] was conducted with a proxy to evaluate significant interference in daily life which was also based on clinical judgement. Also, self- and proxyreported information of cognitive decline, and a neuropsychological assessment were part of the baseline assessment.

\section{Self- and proxy reported cognitive decline}

Self-reported cognitive decline was measured by the Subjective Cognitive Functioning (SCF) questionnaire [27]. Participants had to rate their cognitive change in the past year on a scale from -3 (very strong decline) to +3 (very strong improvement) in the domains of memory and attention. Two groups were identified: those who reported a cognitive decline (in memory or in concentration, or in both) $(\mathrm{SCF}<0)$, and those who reported no change or an improvement in these domains ( $\mathrm{SCF} \geq 0$ ). The Dutch translation of the Détérioriation Cognitive Observée (DECO) [28] was used to measure proxy-reported cognitive decline. It consists of 19 items concerning the degree of change in cognitive functioning in the past year on a scale from 2 (no change) to 0 (great decline). It has been shown to be highly sensitive for changes in cognitive functioning [28]. Furthermore, it shows high discriminability, with a sensitivity of $79 \%$ and specificity of $90 \%$ for detecting dementia using a cutoff score of $\leq 24$, which is not influenced by level of education [29]. This cutoff was used to identify two groups: those who reported a greater decline in cognitive functioning (DECO $\leq 24)$, and those who did not (DECO > 24).

\section{Neuropsychological assessment}

All participants underwent neuropsychological assessment by use of a standardized test battery. The following cognitive domains were measured: general cognitive functioning (MMSE) [30], episodic memory, both for verbal (Dutch version of the verbal learning test; VLT) [31] and visual information (Visual Association Test; VAT) [32], information processing speed (Stroop Color-Word Test part I; SCWT-I [33], and Trail Making Test part A; TMTA [34] or Concept Shifting Task part A; CST-A) [35], executive functioning (interference index of the SCWT) [33], concept shifting (CST-C) [35]), and semantic word fluency (1-minute animal naming) [36]. All cognitive performances were translated to $\mathrm{z}$-scores adjusted for age, education and, if appropriate, sex [23-25, 37]. Extreme z-scores were found for SCWT-I (4.7\% of all scores), SCWT interference $(5.3 \%$ of all scores), CSTA/TMTA (1.1\% of all scores), and concept shifting (1.9\% of all score). These scores were winsorized at a lower $(-5)$ and upper $(+5)$ boundary. Presence and severity of depressive symptoms were measured using the 15 -item Geriatric Depression Scale (GDS-15) [38].

\section{Follow-up assessments}

Follow-up (FU) assessments took place one, two, three, and five years (FU1, FU2, FU3, FU5) after baseline. Comparable to baseline, every follow-up assessment included a medical history and neuropsychological assessment using parallel versions to reduce material-specific test-retest effects. The consultation with a family member, based on the DAD, was also taken again to evaluate interference in daily living and decline from a previous level of functioning (social or occupational). The DECO, SCF, and GDS questionnaires were also included at the follow- 


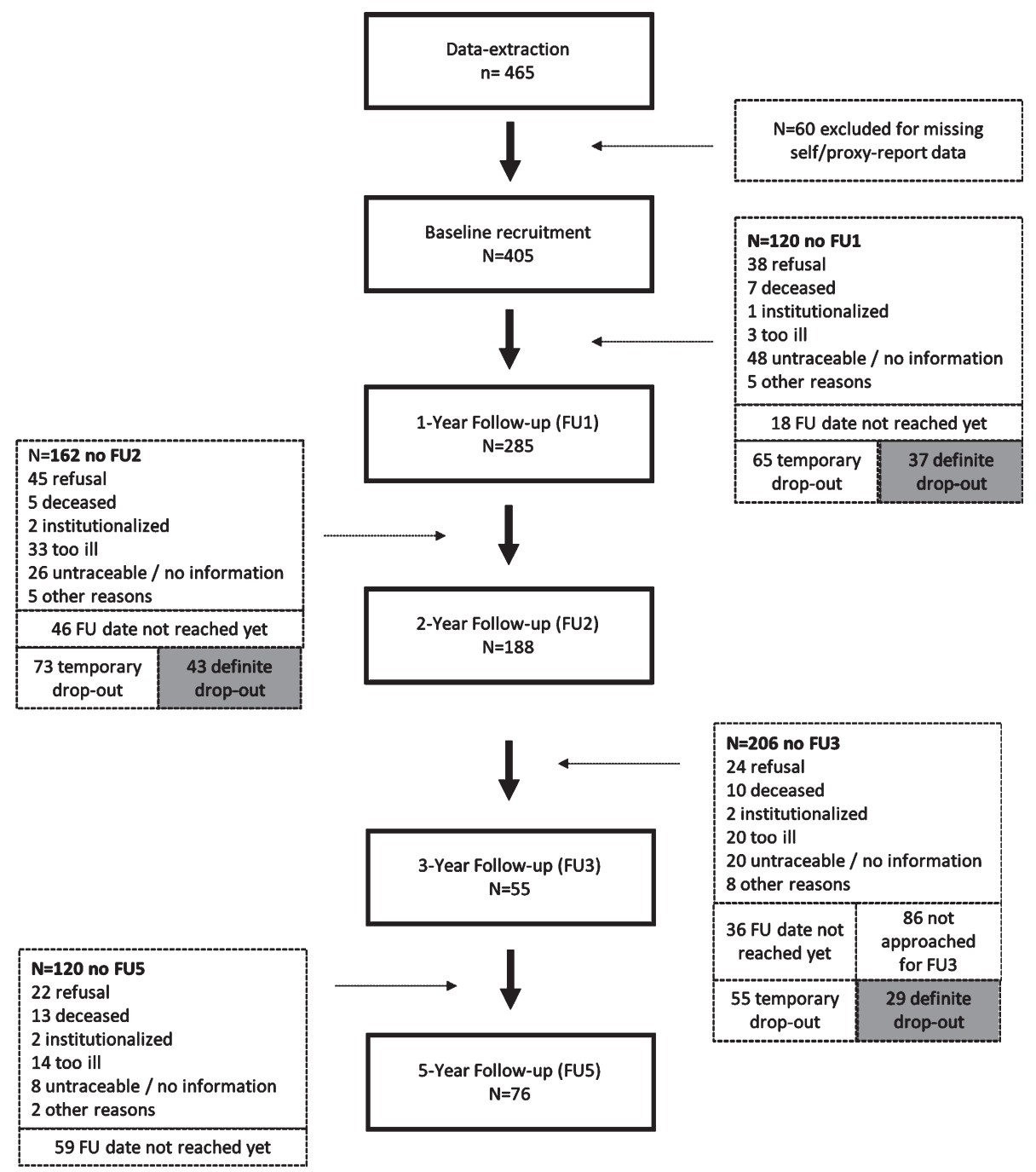

Fig. 1. Flowchart of ongoing longitudinal BBACL cohort.

up assessments. Dementia diagnosis was reviewed at every assessment according to DSM-IV-TR criteria using all available information (outcome of the neuropsychological assessment, medical history, family history, and evaluation of interference in daily live) [39]. In the case of significant interference in daily life was suspected, the medical specialist (psychiatrist) from the memory clinic was consulted. After reviewing all data (e.g., earlier brain scans, current new information), the medical specialist made the dementia diagnosis.

\section{Statistical analysis}

Statistical analyses were performed using SPSS version 20.0 for Mac OS X. Differences in baseline characteristics between the self- and proxy-reported cognitive decline groups and dementia converters and non-converters were compared using independentsample $t$-tests (or Mann-Whitney $\mathrm{U}$ tests in case of no normal distribution), and $\chi^{2}$-tests (categorical variables). To estimate associations between self- or proxy-reported cognitive decline with objective cognitive performance over time, linear mixed models were used with a random intercept and random slope to account for correlated repeated measurements within individuals. The unstructured covariance structure type was chosen as this gave the best model fit using likelihood ratio testing. The cognitive test $z$-scores were used as dependent variables in the model with a separate model for each subtest. The independent terms included the self-reported cogni- 
tive decline group, time (categorical: baseline, FU1, FU2, FU3, FU5), and group by time interaction. The interaction term was added to explore future cognitive decline or improvement between the groups. The null hypothesis of no difference in course of cognitive performance was tested with an $\mathrm{F}$ test to examine whether there was a significant group effect and group-by-time interaction across all time points. Furthermore, estimated means were calculated in this analysis for group by time. All models were adjusted for age, sex, education (low, middle, high), and depressive symptoms. The same model was run with the proxy-reported group as independent term. Because time was added as a categorical variable the differences between the groups could be identified at each measurement. To explore the association between subjective cognitive decline and depressive symptoms the linear mixed model analysis was also run with the GDS-15 score as dependent term and the same independent terms as described above. This model was adjusted for age, sex, and education. Cox regression analyses adjusted for age, sex, education, and depressive symptoms were performed to evaluate if proxy- and self-reported cognitive decline were associated with conversion to dementia. Cause-specific hazard ratios were calculated with competing risk of death $(n=35,9.6 \%)$. The outcome was dementia converters versus non-converters. The survival time was time to diagnosis of dementia (converters) or last available follow-up diagnosis (non-converters). The alpha-level was set at 0.05 in two-sided tests throughout.

\section{RESULTS}

\section{Baseline characteristics}

At baseline, $84.4 \%$ of the patients were identified as having self-reported cognitive decline (SCF $<0$ ) and $27.2 \%$ as having proxy-reported cognitive decline (DECO $\leq 24)$. The combination of both self- and proxy reported cognitive decline was present in $23.5 \%$ of the patients, while in $11.5 \%$ no subjective cognitive decline was reported by either the patient or family member. The baseline demographic characteristics are shown in Table 1. Most proxies were partners $(71.4 \%)$. Other proxies included children (20\%), acquaintances (3\%), siblings $(2.2 \%)$, other family members $(2.2 \%)$, and ex-partners $(1.2 \%)$. Overall, most proxies had daily $(75.6 \%)$ or at least once a week $(21.4 \%)$ contact with the patient. Patients with self- or proxy-reported cog- nitive decline showed no significant differences with respect to demographic features (Table 1). The prevalence of MCI was comparable between participants with and without self- $\left(\chi^{2}(1)=0.64, p=0.425\right)$ or proxy-reported $\left(\chi^{2}(1)=1.63, p=0.202\right)$ cognitive decline. In addition, patients with self- or proxyreported cognitive decline had significantly higher mean scores of depressive symptoms than those without (self-report: $\mathrm{U}=7853, p=0.002$, proxy-report: $\mathrm{U}=11691, p<0.001)$.

\section{Association between self- and proxy-reported cognitive decline and cognitive performance}

The differences in course of cognitive performance for patients with and without self- or proxy-reported cognitive decline are shown in Table 2 and Fig. 2. In these analyses, we did not differentiate between patients with and without cognitive impairment. At baseline, linear mixed models, corrected for age, sex, education, and depressive symptoms, showed no significant differences regarding cognitive performance between patients with and without self-reported decline. In addition, no significant overall interaction effect was found with time. However, averaged over all time points together, patients with self-reported cognitive decline at baseline had a lower performance on the VLT immediate recall $(\mathrm{F}(1,475)=11.68, p=0.001)$, VLT delayed recall $(\mathrm{F}(1,463)=15.50, p<0.001)$, semantic fluency $(\mathrm{F}(1,473)=7.59, p=0.006)$, and SCWT-I $(F(1,456)=10.10, p=0.002)($ Fig. 2 and Table 2) in comparison to patients who did not report a subjective cognitive decline.

Patients with proxy-reported cognitive decline had a lower performance on the CSTA/TMTA and SCWT-I at baseline compared to those without (Table 2). However, no differences were found on the other cognitive tests. Averaged over all time points, while accounting for correlated measures within individuals, patients with proxy-reported cognitive decline had a lower performance on the VLT delayed recall $(\mathrm{F}(1,448)=4.63, p=0.032)$, VAT $(\mathrm{F}(1,435)=23.75, p<0.001)$, semantic fluency $(\mathrm{F}(1,464)=11.14, p=0.001)$, CSTA/TMTA (F $(1,460)=12.72, p \leq 0.001)$, concept shifting $(\mathrm{F} \quad(1,376)=5.53, p=0.019), \quad$ SCWT- $1 \quad(F \quad(1$, $463)=25.62, p<0.001)$, and SCWT-interference $(\mathrm{F}$ $(1,420)=11.13, p=0.001)$, and higher scores on GDS-15 $(\mathrm{F}(1,478)=9.60, p=0.002)$. Also, a significant overall interaction with time shows that the cognitive performance of patients with proxy- 
Table 1

Comparison of demographic characteristics in patients with and without self- or proxy-reported cognitive decline $(n=405)$

\begin{tabular}{|c|c|c|c|c|}
\hline & \multicolumn{2}{|c|}{ Self-reported cognitive decline } & \multicolumn{2}{|c|}{ Proxy-reported cognitive decline } \\
\hline & Present & Absent & Present & Absent \\
\hline$n(\%)$ & $342(84.4)$ & $63(15.6)$ & $110(27.2)$ & $295(72.8)$ \\
\hline Age, y & $70.0 \pm 8.3$ & $70.1 \pm 8.9$ & $71.1 \pm 9.0$ & $69.6 \pm 8.2$ \\
\hline Sex, $n$ female $(\%)$ & $128(37.4)$ & $29(46.0)$ & $42(38.2)$ & $115(39.0)$ \\
\hline \multicolumn{5}{|l|}{ Education $n(\%)$} \\
\hline Low & $128(37.4)$ & $30(47.7)$ & $47(42.7)$ & $111(37.6)$ \\
\hline Middle & $128(37.4)$ & $21(33.3)$ & 37 (33.6) & $112(38.0)$ \\
\hline High & $86(25.2)$ & $12(19.0)$ & $26(23.7)$ & $72(24.4)$ \\
\hline \multicolumn{5}{|l|}{ Diagnosis n (\%) } \\
\hline $\mathrm{NCI}$ & $139(40.6)$ & $29(46.0)$ & $40(36.4)$ & $128(43.4)$ \\
\hline MCI & $203(59.4)$ & $34(54.0)$ & $70(63.6)$ & $167(56.6)$ \\
\hline GDS-15 score & $3.6 \pm 3.0^{\mathrm{a}}$ & $2.6 \pm 2.8$ & $4.6 \pm 3.6^{\mathrm{b}}$ & $3.1 \pm 2.6$ \\
\hline MMSE score & $27.6 \pm 2.4$ & $27.2 \pm 2.5$ & $26.7 \pm 2.6^{\mathrm{a}}$ & $27.8 \pm 2.2$ \\
\hline
\end{tabular}

Demographics are represented in mean \pm SD unless stated otherwise. Education was stratified following the Dutch education system in low (primary), average (lower secondary or vocational), and high (higher secondary education, higher vocational, university) education. Groups were compared using Student's $t$-tests, Mann-Whitney U-tests and Pearson's chi-squared tests where appropriate. ${ }^{\mathrm{a}} p \leq 0.05 .{ }^{\mathrm{b}} p \leq 0.001$. NCI, no cognitive impairment; MCI, mild cognitive impairment; GDS, Geriatric Depression Scale; MMSE, Mini-Mental Status Examination.

reported cognitive decline significantly decreased over time on the VAT $(\mathrm{F}(4,389)=3.75, p=0.005)$, CSTA/TMTA $(\mathrm{F}(4,411)=4.18, p=0.003)$, SCWT-I $(\mathrm{F}(4,406)=5.42, p<0.001)$, and SCWT interference $(\mathrm{F}(4,357)=5.37, p<0.001)$. No significant overall interaction was found on the other cognitive tests.

\section{Self- and proxy-reported cognitive decline and conversion to dementia}

As shown in Table 3, 23.3\% of the participants at baseline converted to dementia within five years. Converters had a higher age $(\mathrm{U}=8110, p<0.001)$, had more often MCI $\left(\chi^{2}(1)=44.7, p<0.001\right)$ and proxy-reported decline $\left(\chi^{2}(1)=6.28, p=0.012\right)$ than nonconverters. Converters were also characterized by lower GDS-15 (U=10680, $p=0.001)$ and MMSE scores $(\mathrm{U}=8928, p<0.001)$. Cox regression, adjusted for age, sex, education, and depressive symptoms, were conducted separately for self- and proxy-reported cognitive decline at baseline to investigate the association with conversion to dementia. Table 4 shows that patients with proxy-reported cognitive decline and mutual self- and proxy-reported cognitive decline at baseline were significantly associated with developing dementia compared to patients who did not report proxy-reported cognitive decline or mutual complaints. Patients with self-reported decline also were related with developing dementia compared to patients without self-reported decline, however statistical significance could not be reached. If neither the patient nor a family member reported cognitive decline, patients developed dementia less often, but statistical significance could not be reached (Table 4).

\section{Association between self- and proxy reported cognitive decline and depressive symptoms}

Taking together the group as a whole (NCI and MCI) linear mixed models, corrected for age, sex, and education showed that participants with self reported cognitive decline had more depressive symptoms averaged over all time points together $(\mathrm{F}$ $(1,462)=31.50, p<0.001)$ and level of symptoms were significantly higher at FU1, FU2, and FU5 (Table 5). Participants with proxy-reported cognitive decline also had reported more depressive symptoms averaged across all time points $(\mathrm{F}(1,478)=9.60$, $p=0.002$ ), and these were significantly higher at baseline and follow-up one (Table 5) compared to no proxy-reported decline. No interaction with time was found for both self- and proxy-reported cognitive decline.

Table 5 and Fig. 3 show the results of the separate linear mixed model analyses in patients with NCI or MCI. In NCI patients, self-reported decline was significantly associated with more depressive symptoms at each follow-up, but not at baseline. A significant overall interaction with time showed that the depressive symptoms in participants who experienced self-reported cognitive decline remained stable over time, while the depressive symptoms decreased over time in the group without self-reported decline. In contrast, no significant differences at each measurement or overall interaction with time were 
Table 2

Differences in cognitive performances between participants with or without self- or proxy-reported cognitive decline per follow-up

\begin{tabular}{|c|c|c|c|c|c|c|c|c|c|c|c|c|}
\hline \multirow[t]{2}{*}{ Parameter } & \multicolumn{2}{|c|}{ Baseline } & \multicolumn{2}{|c|}{ FU1 } & \multicolumn{2}{|c|}{ FU2 } & \multicolumn{2}{|c|}{ FU3 } & \multicolumn{2}{|c|}{ FU5 } & \multicolumn{2}{|c|}{ Group by time ${ }^{c}$} \\
\hline & $\beta$ & $95 \% \mathrm{CI}$ & $\beta$ & $95 \% \mathrm{CI}$ & $\beta$ & $95 \% \mathrm{CI}$ & $\beta$ & $95 \% \mathrm{CI}$ & $\beta$ & $95 \% \mathrm{CI}$ & $\mathrm{F}$ & $\mathrm{p}$ \\
\hline \multicolumn{13}{|l|}{ Self-reported decline } \\
\hline VLT IR & -0.17 & $-0.47,0.12$ & -0.13 & $-0.36,0.10$ & $-0.39^{\mathrm{b}}$ & $-0.64,-0.13$ & $-0.54^{\mathrm{a}}$ & $-1.03,-0.05$ & -0.25 & $-0.66,0.17$ & 0.99 & 0.411 \\
\hline VLT DR & -0.09 & $-0.36,0.19$ & $-0.32^{\mathrm{b}}$ & $-0.56,-0.08$ & $-0.45^{\mathrm{b}}$ & $-0.73,-0.18$ & -0.32 & $-0.84,0.21$ & $-0.60^{\mathrm{b}}$ & $-1.05,-1.6$ & 1.33 & 0.259 \\
\hline VAT & 0.15 & $-0.26,0.56$ & -0.21 & $-0.57,0.15$ & -0.25 & $-0.71,0.20$ & -0.23 & $-1.30,0.83$ & -0.29 & $-0.95,0.38$ & 0.64 & 0.636 \\
\hline Semantic fluency & -0.10 & $-0.30,0.11$ & -0.12 & $-0.30,0.06$ & $-0.24^{\mathrm{a}}$ & $-0.43,-0.04$ & -0.09 & $-0.46,0.29$ & $-0.36^{\mathrm{a}}$ & $-0.68,-0.05$ & 0.73 & 0.572 \\
\hline CST-A / TMT-A & -0.02 & $-0.35,0.31$ & 0.05 & $-0.24,0.34$ & -0.00 & $-0.33,0.32$ & -0.43 & $-1.04,0.17$ & -0.49 & $-1.01,0.04$ & 1.22 & 0.302 \\
\hline Concept shifting & -0.15 & $-0.61,0.32$ & -0.28 & $-0.59,0.04$ & 0.06 & $-0.27,0.40$ & -0.55 & $-1.20,0.09$ & 0.21 & $-0.31,0.74$ & 1.52 & 0.195 \\
\hline SCWT - I & -0.21 & $-0.70,0.29$ & -0.37 & $-0.73,0.01$ & -0.16 & $-0.57,0.25$ & -0.33 & $-1.10,0.44$ & -0.56 & $-1.23,0.10$ & 0.37 & 0.832 \\
\hline SCWT interference & -0.25 & $-0.88,0.37$ & -0.24 & $-0.76,0.27$ & 0.10 & $-0.44,0.63$ & -0.26 & $-1.26,0.74$ & 0.25 & $-0.59,1.08$ & 0.49 & 0.743 \\
\hline \multicolumn{13}{|l|}{ Proxy-reported decline } \\
\hline VLT IR & -0.02 & $-0.27,0.22$ & -0.10 & $-0.40,0.21$ & -0.17 & $-0.54,0.21$ & -0.01 & $-0.57,0.56$ & -0.47 & $-1.00,0.07$ & 0.64 & 0.635 \\
\hline VLT DR & -0.01 & $-0.25,0.22$ & -0.23 & $-0.55,0.08$ & -0.23 & $-0.62,0.17$ & -0.40 & $-1.00,0.20$ & -0.35 & $-0.92,0.22$ & 0.75 & 0.557 \\
\hline VAT & -0.17 & $-0.52,0.18$ & $-0.60^{\mathrm{b}}$ & $-1.05,-0.15$ & $-0.93^{\mathrm{b}}$ & $-1.57,-0.29$ & $-2.39^{\mathrm{b}}$ & $-3.62,-1.15$ & -0.57 & $-1.44,0.30$ & 3.75 & $0.005^{\mathrm{b}}$ \\
\hline Semantic fluency & 0.09 & $-0.26,0.08$ & -0.05 & $-0.28,0.18$ & -0.27 & $-0.57,0.03$ & $-0.60^{\mathrm{b}}$ & $-1.04,-0.15$ & -0.38 & $-0.79,0.03$ & 1.87 & 0.115 \\
\hline CST-A / TMT-A & $-0.30^{\mathrm{a}}$ & $-0.57 .-0.03$ & 0.01 & $-0.36,0.37$ & -0.16 & $-0.62,0.29$ & -0.61 & $-1.28,0.05$ & $-1.46^{\mathrm{b}}$ & $-2.12,-0.81$ & 4.18 & $0.003^{b}$ \\
\hline Concept shifting & -0.07 & $-0.44,0.30$ & -0.12 & $-0.53,0.29$ & -0.48 & $-0.98,0.03$ & -0.63 & $-1.38,0.11$ & -0.53 & $-1.26,0.20$ & 1.05 & 0.383 \\
\hline SCWT - I & $-0.48^{\mathrm{a}}$ & $-0.89,-0.07$ & -0.37 & $-0.84,0.10$ & -0.26 & $-0.83,0.31$ & $-1.13^{\mathrm{b}}$ & $-1.98,-0.29$ & $-2.30^{\mathrm{b}}$ & $-3.11,-1.49$ & 5.42 & $<0.001^{\mathrm{b}}$ \\
\hline SCWT interference & 0.38 & $-0.12,0.88$ & -0.25 & $-0.91,0.42$ & 0.36 & $-0.41,1.13$ & $-1.70^{\mathrm{b}}$ & $-2.77,-0.63$ & $-1.58^{\mathrm{b}}$ & $-2.66,-0.50$ & 5.37 & $<0.001^{\mathrm{b}}$ \\
\hline
\end{tabular}

Groups were compared using linear mixed models. Model: cognitive z score (dependent), time, group, group by time, sex, age, education, and depressive symptoms. Groups were compared using linear mixed models and differences are represented in $\beta$. FU, follow up; CI, confidence interval; VLT, verbal learning test; IR, immediate recall; DR, delayed recall; VAT, Visual Association Test; CST, Concept Shifting Test; TMT, Trail Making Test; SCWT, Stroop Color and Word Test. ${ }^{\mathrm{a}} p<0.05 .{ }^{\mathrm{b}} p<0.01 .{ }^{\mathrm{c}}$ Overall interaction between group and time. 

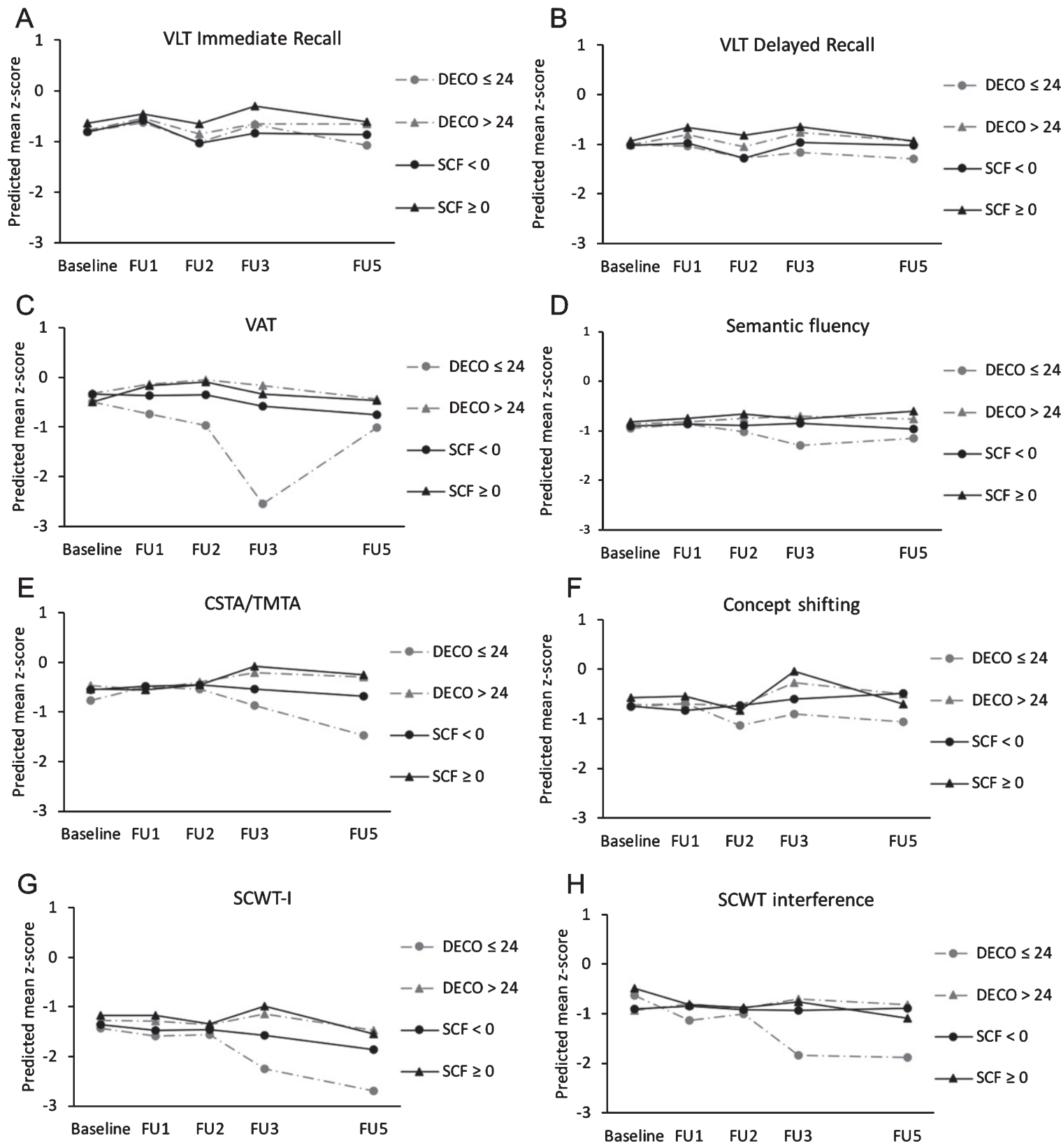

Fig. 2. Course of cognitive performances by subjective cognitive decline groups. DECO $\leq 24$ : proxy-reported cognitive decline, DECO $>$ 24: no proxy-reported cognitive decline, $\mathrm{SCF}<0$ : self-reported cognitive decline, $\mathrm{SCF} \geq 0$ : no self-reported cognitive decline. A) Course of VLT IR scores. B) Course of VLT DR. C) Course of VAT scores. D) Course of fluency scores. E) Course of CSTA/TMTA scores. F) Course of concept shifting scores. G) Course of SCWT-I scores. H) Course of SCWT interference scores. The groups were compared using random-effects analysis with random intercept, random slope and unstructured covariance structure, adjusted for age, gender, education, and depressive symptoms. Predicted mean scores are estimated marginal means of subjective cognitive decline group by time. Higher mean scores represent a better cognitive performance (z-score). SCF, subjective cognitive functioning; DECO, Détérioration Cognitive Observée; VLT, 15-Word Learning Test; DR, delayed recall; IR, immediate recall; VAT, Visual Association Test; CST, Concept Shifting Test; TMT, Trail Making Test; SCWT, Stroop Color and Word Test. 
Table 3

Summary characteristics of patients with and without conversion to dementia

\begin{tabular}{lccc}
\hline & $\begin{array}{c}\text { Converters } \\
(n=94)\end{array}$ & $\begin{array}{c}\text { Nonconverters } \\
(n=311)\end{array}$ & $p$ \\
\hline Age, y & $75.1 \pm 6.8$ & $68.5 \pm 8.3$ & $<0.001$ \\
Sex, $n$ female (\%) & $44(46.8)$ & $113(36.3)$ & 0.068 \\
Education $n(\%)$ & & & 0.171 \\
$\quad$ Low & $31(33.0)$ & $127(40.8)$ & \\
$\quad$ Middle & $37(39.3)$ & $112(36.0)$ & \\
$\quad$ High & $26(27.7)$ & $72(23.2)$ & \\
Diagnosis $n(\%)$ & $11(11.7)$ & $157(50.5)$ & \\
$\quad$ NCI & $83(88.3)$ & $154(49.5)$ & \\
$\quad$ MCI & $83(88.3)$ & $259(83.3)$ & 0.001 \\
Subjective cognitive decline $\mathrm{n}(\%)$ & $35(37.2)$ & $75(24.1)$ & \\
$\quad$ Self-reported & $2.5 \pm 2.1$ & $3.8 \pm 3.1$ & 0.001 \\
$\quad$ Proxy-reported & $26.2 \pm 2.8$ & $27.9 \pm 2.1$ & $<0.001$ \\
GDS-15 score & & \\
MMSE score & & & \\
\hline
\end{tabular}

Demographics are represented in mean \pm SD unless stated otherwise. Education was stratified following the Dutch education system in low (primary), average (lower secondary or vocational), and high (higher secondary education, higher vocational, university) education. Groups were compared using Student's $t$-tests, Mann-Whitney U-tests and Pearson's chi-squared tests where appropriate. NCI, no cognitive impairment; MCI, mild cognitive impairment; GDS, Geriatric Depression Scale; MMSE, Mini-Mental Status Examination.

Table 4

Cox regression models for time to dementia diagnosis.

\begin{tabular}{lccc}
\hline & No of cases & Hazard ratio (95\% CI) & $p$ \\
\hline Self-reported cognitive decline & $83 / 342(24 \%)$ & $1.26(0.65$ to 2.43$)$ & 0.489 \\
versus no self-reported decline & $11 / 63(18 \%)$ & & \\
Proxy-reported cognitive decline & $35 / 110(32 \%)$ & $1.76(1.12$ to 2.78$)$ & $0.015^{\mathrm{a}}$ \\
versus no proxy-reported decline & $59 / 295(20 \%)$ & & \\
No self or proxy reported cognitive decline & $8 / 48(17 \%)$ & $0.68(0.32$ to 1.43$)$ & 0.307 \\
versus self- or proxy-reported decline & $86 / 357(24 \%)$ & & \\
Both self and proxy reported cognitive decline & $32 / 95(34 \%)$ & $1.73(1.09$ to 2.76$)$ & $0.021^{\mathrm{a}}$ \\
versus no self and proxy reported decline & $62 / 310(20 \%)$ & & \\
\hline
\end{tabular}

Each row represents a separate cox regression analysis adjusted for sex, age, education, and depressive symptoms. Number of cases indicates how many participants of the group were diagnosed with dementia. CI, confidence interval. ${ }^{\mathrm{a}} p<0.05$.

found for the proxy-reported decline group as compared to no proxy-reported decline. In MCI patients, self-reported decline was associated with more depressive symptoms at baseline, FU1 and FU5. Proxy-reported decline was associated with more depressive symptoms at baseline and FU1. No significant interaction with time was found for either self- or proxy reported cognitive decline.

\section{DISCUSSION}

This study aimed to gain further insight into the association between self- and proxy-reported cognitive decline and objective cognitive performance, depressive symptoms, and dementia conversion in memory clinic visitors. At baseline, self-reported cognitive decline was not associated with lower cognitive performance, while proxy-reported decline was associated with a lower performance on two subtests. However, averaged over the course of five years, both self- and proxy-reported decline were associated with generalized lower objective cognitive performance. Proxy-reported decline also related to a significant decline over time on cognitive tests and to developing dementia, while self-reported decline did not reach statistical significance. Participants more often developed dementia when self-reported decline was confirmed by a proxy. Furthermore, both self- and proxy reported decline were associated with higher rates of depressive symptoms. In patients without cognitive impairment self-reported decline was significantly associated with more depressive symptoms while proxy-reported decline was not.

Our findings are in line with previous studies that found an association with subjectively perceived cognitive decline and objective cognitive perfor- 
Table 5

Differences between participants with and without self or proxy-reported decline in depressive symptoms per follow-up moment

\begin{tabular}{|c|c|c|c|c|c|c|c|c|c|c|c|c|}
\hline \multirow[t]{2}{*}{ Parameter } & \multicolumn{2}{|c|}{ Baseline } & \multicolumn{2}{|c|}{ FU1 } & \multicolumn{2}{|c|}{ FU2 } & \multicolumn{2}{|c|}{ FU3 } & \multicolumn{2}{|c|}{ FU5 } & \multicolumn{2}{|c|}{ Group by time $^{c}$} \\
\hline & $\beta$ & $95 \% \mathrm{CI}$ & $\beta$ & $95 \% \mathrm{CI}$ & $\beta$ & $95 \% \mathrm{CI}$ & $\beta$ & $95 \% \mathrm{CI}$ & $\beta$ & $95 \% \mathrm{CI}$ & $\mathrm{F}$ & $p$ \\
\hline \multicolumn{13}{|l|}{ Both NCI and MCI } \\
\hline \multicolumn{13}{|l|}{ Self-reported decline } \\
\hline GDS-15 & 0.55 & $-0.12,1.22$ & $1.30^{\mathrm{b}}$ & $0.75,1.85$ & $1.00^{\mathrm{b}}$ & $0.38,1.63$ & 1.08 & $-0.12,2.28$ & $1.78^{\mathrm{b}}$ & $0.77,2.80$ & 1.27 & 0.282 \\
\hline \multicolumn{13}{|l|}{ Proxy-reported decline } \\
\hline GDS-15 & $0.90^{\mathrm{b}}$ & $0.34,1.46$ & $1.06^{\mathrm{b}}$ & $0.34,1.78$ & 0.68 & $-0.24,1.60$ & 0.37 & $-1.02,1.76$ & 1.01 & $-0.32,2.35$ & 0.27 & 0.895 \\
\hline \multicolumn{13}{|l|}{ NCI patients only } \\
\hline \multicolumn{13}{|l|}{ Self-reported decline } \\
\hline GDS-15 & -0.47 & $-1.43,0.49$ & $1.41^{\mathrm{b}}$ & $0.59,2.23$ & $1.52^{\mathrm{b}}$ & $0.63,2.41$ & $1.85^{\mathrm{a}}$ & $0.09,3.62$ & $2.20^{\mathrm{b}}$ & $0.75,3.65$ & 3.45 & $0.009^{b}$ \\
\hline \multicolumn{13}{|l|}{ Proxy-reported decline } \\
\hline GDS- 15 & 0.80 & $-0.05,1.66$ & 0.30 & $-1.12,1.72$ & 0.86 & $-0.62,2.34$ & 0.41 & $-1.88,2.69$ & 1.85 & $-0.60,4.31$ & 0.38 & 0.822 \\
\hline \multicolumn{13}{|l|}{ MCI patients only } \\
\hline \multicolumn{13}{|l|}{ Self-reported decline } \\
\hline GDS-15 & $1.50^{\mathrm{b}}$ & $0.58,2.41$ & $1.14^{\mathrm{b}}$ & $0.39,1.90$ & 0.64 & $-0.23,1.50$ & 0.58 & $-1.04,2.20$ & $1.46^{\mathrm{b}}$ & $0.07,2.85$ & 0.71 & 0.587 \\
\hline \multicolumn{13}{|l|}{ Proxy-reported decline } \\
\hline GDS-15 & $0.99^{\mathrm{b}}$ & $0.34,1.46$ & $1.23^{\mathrm{b}}$ & $0.38,2.08$ & 0.49 & $-0.69,1.67$ & 0.38 & $-1.40,2.16$ & 0.66 & $-0.98,2.30$ & 0.39 & 0.815 \\
\hline
\end{tabular}

Groups were compared using linear mixed models. Model: depressive symptoms (dependent), time, group, group by time, sex, age, and education. Groups were compared using linear mixed models and differences are represented in $\beta$. FU, follow up; CI, confidence interval; GDS, Geriatric Depression Scale. ${ }^{\mathrm{a}} p<0.05 .{ }^{\mathrm{b}} p<0.01$. ${ }^{\mathrm{c}} \mathrm{Overall}$ interaction between group and time. 
A

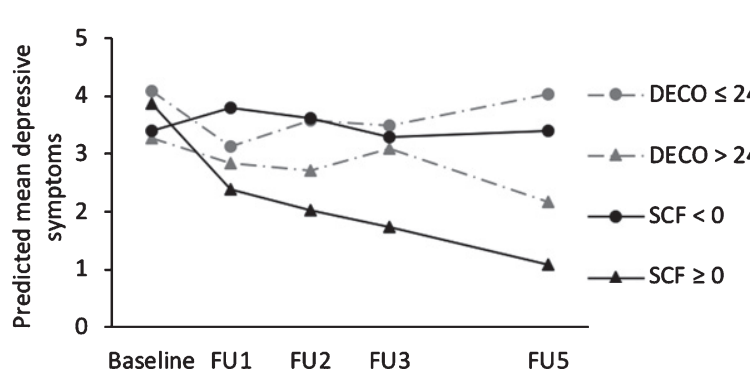

B

GDS-15

Fig. 3. Course of depressive symptoms by subjective cognitive decline groups. DECO $\leq 24$ : proxy-reported cognitive decline, $\mathrm{DECO}>24$ : no proxy-reported cognitive decline, SCF $<0$ : self-reported cognitive decline, SCF $\geq 0$ : no self-reported cognitive decline. A: Course of depressive symptoms in patients with NCI. B: Course of depressive symptoms in patients with MCI. These figures are based on random-effects analyses adjusted for age, gender, and education. The predicted mean scores are estimated marginal means of time by group. Higher mean scores represent a higher level of depressive symptoms. SCF, subjective cognitive functioning; DECO, Détérioration Cognitive Observée; GDS, Geriatric Depression Scale.

mance, but contrasts with other studies [8-11, 17]. An explanation for these conflicting findings could be the differences in methodology, such as use of different populations, questionnaires and conceptual discrepancies $[2,40]$. We found that proxy reported decline was more often associated with a lower performance on cognitive tests, cognitive decline, and conversion to dementia than self-reported decline. This is consistent with earlier studies that showed that proxy-reported cognitive decline is a better predictor of cognitive performance and development of dementia than self-reported decline in patients with no cognitive impairment and mild AD dementia [19, 21]. Only a handful studies, however, have contrasted self- and informant reported cognitive decline in a memory clinic population. Studies conducted in a memory-clinic population reported that experiencing more mutual complaints were associated with a worse cognitive trajectory, while other cross-sectional studies demonstrated that self- or proxy-reported decline did not result in any cognitive differences $[16,41$, 42]. This study extends evidence to a clinical population from a memory clinic ranging from no cognitive disorders to MCI with a longer follow-up period. The lack of association between cognition and self- and proxy-reported decline at baseline might be explained by the difference between subjective and objective measurements. The questionnaires (SCF and DECO) require a subjective judgment of cognitive complaints in the past year, while cognitive performance is an objective measure at a single time point in which the premorbid level cannot be taken into account. The cross-sectional objective measurements might not be sensitive enough to determine subtle intraindividual changes as reflected in the subjective report of the complaints, as proposed by a recent review [2]. Although proxy-reported cognitive decline was related to almost all cognitive test performances, it was shown that self-reported decline was related to a lower performance on selective cognitive tests only. Patients with self-reported cognitive decline performed worse on tasks concerning episodic memory and verbal fluency. These cognitive domains have been extensively described in the literature as one of the first characteristics of cognitive decline in prodromal AD [43, 44]. Decreased episodic memory scores could be a first sign of underlying AD pathology, such as medial temporal lobe damage or elevated amyloid- $\beta$ burden, which in turn is also associated with self-reported decline [45]. These findings contrast with recent studies in memory-clinic visitors in which self-reported decline was not associated with cognitive differences $[15,42]$. This could, however, be explained by smaller sample sizes, the use of a nonstandardized way to measure self-reported cognitive decline or cross-sectional analyses. Recently, more evidence has become available showing that the combination of self-reported cognitive decline with $\mathrm{AD}$ positive biomarkers improves the ability of predicting objective cognitive decline and dementia $[15,46]$.

In both proxy- and self-reported cognitive decline an association with depressive symptoms was found. The finding that participants without cognitive impairment reported more depressive symptoms remained significant for the self-reported cognitive decline group, while this was not found for proxyreported decline. Depressive symptoms have been considered one of the most influential factors associated with subjective cognitive decline in the absence of cognitive impairment [11, 47]. The question 
remains what underlies the co-existence of subjective complaints and depressive symptoms. On one hand, the "cognitive model of depression" emphasizes that depressed patients often view themselves, others, and their future in a negatively distorted way [48]. This negative cognitive bias has been thought to mediate the impaired ability to accurately selfassess cognitive functioning [49]. A recent study shows an underestimation of cognitive functioning in depressed patients and an overestimation in healthy participants [50]. On the other hand, previous studies have found that depressive symptoms and major depression are related to lower hippocampal volumes and increased vascular brain lesions, which could cause cognitive impairment [51, 52]. The DSM-IV criteria of a Major Depressive Disorder also include having difficulties concentrating and an impaired ability to make decisions [53]. Conversely, it is also debated that depressive symptoms could be the result of realizing cognitive decline [54]. It is highly likely that these theories play a role in the association between subjective cognitive decline and depressive symptoms. Another explanation of the association between self-reported decline and depressive symptoms could be the high prevalence of depressive symptoms among patients referred to a memory clinic [55]. Since the memory clinic in this study is embedded within the psychiatric department, the prevalence could be even higher. Therefore, depressive symptoms might indicate underlying depressive symptomatology in memory clinic visitors which asks for a multidisciplinary approach in the evaluation of cognitive complaints.

Our study shows that proxy-reported cognitive decline is predictive for cognitive decline and developing dementia, while statistical significance was not reached for self-reported cognitive decline. This is in line with previous studies suggesting that informant report may enable identification of very early decline and that only a small proportion of participants with self-reported decline in a memory clinic develop dementia [2, 15]. In turn, other findings pointing towards a higher risk of conversion to MCI or dementia for memory clinic patients with selfreported decline $[3,56]$ However, our findings should be carefully interpreted because participants with self-reported cognitive decline seems to be a heterogeneous group and therefore less sensitive and discriminative for decline in cognitive performance. The high prevalence might have led to lack of contrast when comparing those with and without subjective cognitive decline to the cognitive outcomes.
For the dementia outcome, large standard errors and wide $95 \%$ confidence intervals indeed suggest large variability, which might have led to a relatively high and non-significant $p$-value despite an HR around 1.5 (and similar to the one found for proxyreported decline). Obviously, subjective cognitive decline denotes a still very heterogeneous group of patients that was of limited predictive value. In contrast, proxy-reported decline seems to have a higher sensitivity for cognitive outcome and for conversion to dementia. This could be explained by less influence of reporting bias [57]. Proxy-reports have also been described as a more objective measure because they can give insight into more implicit processes which are often not noticed by the patient due to subtle changes [58]. When both self- and proxy-reported cognitive decline was present, this identified a group that more often converted to dementia than those with proxy-reported decline alone. This is in line with diagnostic criteria, which often includes cognitive complaints corroborated by family members [22]. In addition, mutual proxy- and self-reported cognitive decline have been shown to be associated with AD neuropathology [41]. These findings underline the importance of taken informant-based information into account in diagnostics at memory clinic settings.

For the current study, both strengths and limitations have to be kept in mind when interpreting the findings. The strengths of this study are the large sample size and the long follow-up period of up to five years. In addition, not many studies have focused on subjective cognitive decline in memory clinic visitors with and without cognitive impairment. In addition, a broad range of inclusion criteria were chosen to maximize generalizability in a clinical population. However, some limitations should be mentioned. Self-reported cognitive decline was measured using a new questionnaire that needs further psychometric evaluation. This questionnaire consists of two questions in which patients could indicate the range of the experienced change (from strong decline to strong improvement) on both memory and attention. This is likely to have a better validity and reliability than the use of one single question in which the patients only answers with yes or no, which has been used in several other studies [59]. Other studies have used more extensive questionnaires, such as the Cognitive Failures Questionnaire, but this does not include the opportunity to report improvements and focuses on memory complaints. Nonetheless, standardization of measurements for self-reported cognitive decline is important, which is also highlighted in the recently 
proposed framework for subjective cognitive decline $[2,40]$ In addition, we should consider that only 67 participants could be included in the five-year followup measurement, which is partly due to the ongoing nature of this cohort study. For example, 159 participants (39.6\%) were included in the study after 2013 and therefore did not reach their fifth-year assessment yet. In addition, the number of participants at the three-year follow-up was relatively small due to the study design, which did not include a regular threeyear follow-up assessment initially. This resulted in less data for cognitive tests and therefore could have led to less robust findings (e.g., VAT follow-up 3, Fig. 2). The drop-outs may have resulted in nondifferential attrition bias. When comparing groups at baseline, the drop-outs were frailer, that is, older and performing worse on most cognitive tests, leaving a less impaired sample in the analyses. This might have led to an underestimation of group differences due to the attrition of patients with cognitive impairment. However, the maximum likelihood estimation in the repeated-measures design takes this into account and is relatively robust against missing data points when covariates related to missing data are included [60]. It is also important to note that this study has been conducted in memory clinic visitors, and its outcome can therefore not be generalized to the general population.

In summary, the present study shows that both selfand proxy-reported cognitive decline was related to lower cognitive performance and more depressive symptoms. Proxy-reported decline indicated future cognitive decline and conversion to dementia. When subjective cognitive decline is confirmed by both the patient and informant it showed the strongest relation with subsequent dementia onset. The current findings may be useful for earlier identification of patients atrisk for dementia. This could lead to a larger time frame to implement interventions, guidance, and an increased understanding of the disease process. It has been shown that early interventions can be beneficial for caregivers in the pre-dementia phase when levels of stress and burden are still relatively low [61-63]. Our findings suggest that when a patient is referred to a memory clinic, the role of both depressive symptomatology and proxy-reported cognitive decline is very important to take into account.

\section{ACKNOWLEDGMENTS}

We are very grateful to all the participants in the BBACL-cohort and to all our colleagues playing a role in the BBACL-study. Also, many thanks for Nico Rozendaal and Ron Mengelers for the data management. This work was performed as a partial fulfilment towards the International Master in Affective Neuroscience of Maastricht University and the University of Florence. This study was supported by an independent grant of the Noaber Foundation and the Alzheimer Nederland.

Authors' disclosures available online (https:// www.j-alz.com/manuscript-disclosures/18-0857r3).

\section{REFERENCES}

[1] Ponds RW, Comissaris KJ, Jolles J (1997) Prevalence and covariates of subjective forgetfulness in a normal population in the Netherlands. Int J Aging Hum Dev 45, 207-221.

[2] Jessen F, Amariglio RE, van Boxtel M, Breteler M, Ceccaldi M, Chételat G, Dubois B (2014) A conceptual framework for research on subjective cognitive decline in preclinical Alzheimer's disease. Alzheimers Dement 10, 844-852.

[3] Mitchell AJ, Beaumont H, Ferguson D, Yadegarfar M, Stubbs B (2014) Risk of dementia and mild cognitive impairment in older people with subjective memory complaints: Meta-analysis. Acta Psychiatr Scand 130, 439-451.

[4] Buckley RF, Maruff P, Ames D, Bourgeat P, Martins RN, Masters CL, Rainey-Smith S, Lautenschlager N, Rowe CC, Savage G, Villemagne VL, Ellis KA (2016) Subjective memory decline predicts greater rates of clinical progression in preclinical Alzheimer's disease. Alzheimers Dement 12, 796-804.

[5] Benito-Leon J, Mitchell AJ, Vega S, Bermejo-Pareja F (2010) A population-based study of cognitive function in older people with subjective memory complaints. $J$ Alzheimers Dis 22, 159-170.

[6] Mitchell AJ (2008) The clinical significance of subjective memory complaints in the diagnosis of mild cognitive impairment and dementia: A meta-analysis. Int J Geriatr Psychiatry 23, 1191-1202.

[7] Miranda B, Madureira S, Verdelho A, Ferro J, Pantoni L, Salvadori E, Chabriat H (2008) Self-perceived memory impairment and cognitive performance in an elderly independent population with age-related white matter changes. J Neurol Neurosurg Psychiatry 79, 869-873.

[8] Koppara A, Wagner M, Lange C, Ernst A, Wiese B, König H (2015) Cognitive performance before and after the onset of subjective cognitive decline in old age. Alzheimers Dement (Amst) 1, 194-205.

[9] Dufouil C, Fuhrer R, Alpérovitch A (2005) Subjective cognitive complaints and cognitive decline: Consequence or predictor? The Epidemiology of Vascular Aging Study. $J$ Am Geriatr Soc 53, 616-621.

[10] Glodzik-Sobanska L, Reisberg B, De Santi S, Babb JS, Pirraglia E, Rich KE, Brys M, de Leon MJ (2007) Subjective memory complaints: Presence, severity and future outcome in normal older subjects. Dement Geriatr Cogn Disord 24, 177-184.

[11] Zlatar ZZ, Muniz M, Galasko D, Salmon DP (2018) Subjective cognitive decline correlates with depression symptoms and not with concurrent objective cognition in a clinic-based sample of older adults. J Gerontol B Psychol Sci Soc Sci 73, 1198-1202. 
[12] Hohman TJ, Beason-Held LL, Resnick SM (2011) Cognitive complaints, depressive symptoms, and cognitive impairment: Are they related? J Am Geriatr Soc 59, 19081912.

[13] Zlatar ZZ, Moore RC, Palmer BW, Thompson WK, Jeste DV (2014) Cognitive complaints correlate with depression rather than concurrent objective cognitive impairment in the SAGE baseline sample. J Geriatr Psychiatry Neurol 27, 181-187.

[14] Slavin MJ, Brodaty H, Kochan NA, Crawford JD, Trollor JN, Draper B, Sachdev PS (2010) Prevalence and predictors of "subjective cognitive complaints" in the Sydney Memory and Ageing Study. Am J Geriatr Psychiatry 18, 701-710.

[15] Hessen E, Eckerstrom M, Nordlund A, Selseth Almdahl I, Stalhammar J, Bjerke M, Eckerstrom C, Gothlin M, Fladby T, Reinvang I, Wallin A (2017) Subjective cognitive impairment is a predominantly benign condition in memory clinic patients followed for 6 years: The Gothenburg-Oslo MCI Study. Dement Geriatr Cogn Dis Extra 7, 1-14

[16] Perrotin A, La Joie R, de La Sayette V, Barre L, Mezenge F, Mutlu J, Guilloteau D, Egret S, Eustache F, Chetelat G (2017) Subjective cognitive decline in cognitively normal elders from the community or from a memory clinic: Differential affective and imaging correlates. Alzheimers Dement 13, 550-560.

[17] Nicholas CR, Dowling NM, Racine AM, Clark LR, Berman SE, Koscik RL, Asthana S, Hermann B, Sager MA, Johnson SC (2017) Longitudinal assessment of self- and informant-subjective cognitive complaints in a sample of healthy late-middle aged adults enriched with a family history of Alzheimer's disease. J Int Neuropsychol Soc 23, 617-626.

[18] Slavin MJ, Sachdev PS, Kochan NA, Woolf C, Crawford JD, Giskes K, Reppermund S, Trollor JN, Draper B, Delbaere K, Brodaty H (2015) Predicting cognitive, functional, and diagnostic change over 4 years using baseline subjective cognitive complaints in the Sydney Memory and Ageing Study. Am J Geriatr Psychiatry 23, 906-914.

[19] Rabin LA, Wang C, Katz MJ, Derby CA, Buschke H, Lipton RB (2012) Predicting Alzheimer's disease: Neuropsychological tests, self-reports and informant reports of cognitive difficulties. J Am Geriatr Soc 60, 1128-1134.

[20] Valech N, Mollica MA, Olives J, Tort A, Fortea J, Lleo A, Belen SS, Molinuevo JL, Rami L (2015) Informants' perception of subjective cognitive decline helps to discriminate preclinical Alzheimer's disease from normal aging. $J$ Alzheimers Dis 48(Suppl 1), S87-S98.

[21] Caselli RJ, Chen K, Locke DE, Lee W, Roontiva A, Bandy D, Fleisher AS, Reiman EM (2014) Subjective cognitive decline: Self and informant comparisons. Alzheimers Dement 10, 93-98.

[22] Albert MS, DeKosky ST, Dickson D, Dubois B, Feldman HH, Fox NC, Gamst A, Holtzman DM, Jagust WJ, Petersen RC, Snyder PJ, Carrillo MC, Thies B, Phelps CH (2011) The diagnosis of mild cognitive impairment due to Alzheimer's disease: Recommendations from the National Institute on Aging-Alzheimer's Association workgroup on diagnostic guidelines for Alzheimer's disease. Alzheimers Dement 7, 270-279.

[23] Van der Elst W, Van Boxtel MP, Van Breukelen GJ, Jolles J (2006) Normative data for the Animal, Profession and Letter M Naming verbal fluency tests for Dutch speaking participants and the effects of age, education and sex. J Int Neuropsychol Soc 12, 80-89.
[24] Van der Elst W, Van Boxtel MP, Van Breukelen GJ, Jolles J (2006) The Stroop color-word test: Influence of age, sex and education; and normative data for a large sample across the adult age range. Assessment 13, 62-79.

[25] Van der Elst W, van Boxtel MPJ, van Breukelen GJ, Jolles J (2005) Rey's verbal learning test: Normative data from 1855 healthy participants aged 24-81 years and the influence of age, sex, education, and mode of presentation. $J$ Int $\mathrm{Neu}$ ropsychol Soc 11, 290-302.

[26] Gelinas I, Gauthier L, McIntyre M, Gauthier S (1999) Development of a functional measure for persons with Alzheimer's disease: The disability assessment for dementia. Am J Occup Ther 53, 471-481.

[27] Aalten P, Ramakers IHGB, Biessels GJ, de Deyn PP, Koek HL, OldeRikkert MGM, Oleksik AM, Richard E, Smits LL, van Swieten JC, Teune LK, van der Lugt A, Barkhof F, Teunissen CE, Rozendaal N, Verhey FRJ, van der Flier WM (2014) The Dutch Parelsnoer Institute - Neurodegenerative diseases; methods, design and baseline results. BMC Neurol 14, 254

[28] Ritchie K, Fuhrer R (1992) A comparative study of the performance of screening tests for senile dementia using receiver operating characteristics analysis. J Clin Epidemiol 45, 627-637.

[29] Ritchie K, Fuhrer R (1996) The validation of an informant screening test for irreversible cognitive decline in the elderly: Performance characteristics within a general population sample. Int J Geriatr Psychiatry 11, 149-156.

[30] Kok R, Verhey F (2002) Dutch translation of the mini mental state examination (Folstein et al., 1975).

[31] Lezak MD, Howieson DB, Bigler ED, Tranel D (2012) Neuropsychological Assessment, Oxford University Press, New York.

[32] Lindeboom J, Schmand B (2002) Visual association test to detect early dementia of the Alzheimer type. J Neurol Neurosurg Psychiatry 73.

[33] Houx PJ, Jolles J, Vreeling FW (1993) Stroop interference: Aging effects assessed with the Stroop Color-Word Test. Exp Aging Res 19, 209-224.

[34] Reitan RM (1985) Validity of the Trail Making Test as an indication of organic brain damage. Percept Mot Skills $\mathbf{8}$, 271-276.

[35] Vink M, Jolles J (1985) A new version of the Trail-Making Test as an informant processing task. J Clin Neuropsychol $7,162$.

[36] Tombaugh T, Kozak J, Rees L (1999) Normative data stratified by age and education for two measures of verbal fluency: FAS and animal naming. Arch Clin Neuropsychol 14, 167-177.

[37] Schmand B, Houx P, de Koning I (2003) Normen voor Stroop kleur-woord tests, Trail Making test en Story Recall van Rivermead Behavioural Memory Test. Nederlands Instituut voor Psychologen, Sectie Neuropsychologie, Amsterdam.

[38] De Craen AJM, Heeren TJ, Gussekloo J (2003) Accuracy of the 15-item Geriatric Depression Scale (GDS-15) in a community sample of the oldest old. Int J Geriatr Psychiatry 18, 63-66.

[39] Association AP (1994) Diagnostics and Statistical Manual of Mental Disorders, fourth edition. American Psychiatric Association, Washington, DC.

[40] Rabin LA, Smart CM, Crane PK, Amariglio RE, Berman LM, Boada M, Buckley RF, Chetelat G, Dubois B, Ellis KA, Gifford KA, Jefferson AL, Jessen F, Katz MJ, Lipton RB, Luck T, Maruff P, Mielke MM, Molinuevo JL, 
Naeem F, Perrotin A, Petersen RC, Rami L, Reisberg B, Rentz DM, Riedel-Heller SG, Risacher SL, Rodriguez O, Sachdev PS, Saykin AJ, Slavin MJ, Snitz BE, Sperling RA, Tandetnik C, van der Flier WM, Wagner M, Wolfsgruber S, Sikkes SA (2015) Subjective cognitive decline in older adults: An overview of self-report measures used across 19 international research studies. J Alzheimers Dis 48(Suppl 1), S63-86.

[41] Gifford KA, Liu D, Hohman TJ, Xu M, Han X, Romano RR, 3rd, Fritzsche LR, Abel T, Jefferson AL (2015) A mutual self- and informant-report of cognitive complaint correlates with neuropathological outcomes in mild cognitive impairment. PloS One 10, e0141831.

[42] Silva MR, Moser D, Pfluger M, Pusswald G, Stogmann E, Dal-Bianco P, Auff E, Lehrner J (2016) Self-reported and informant-reported memory functioning and awareness in patients with mild cognitive impairment and Alzheimer s disease. Neuropsychiatry 30, 103-112.

[43] Hamel R, Kohler S, Sistermans N, Koene T, Pijnenburg Y, van der Flier W, Scheltens P, Aalten P, Verhey F, Visser PJ, Ramakers I (2015) The trajectory of cognitive decline in the pre-dementia phase in memory clinic visitors: Findings from the 4C-MCI study. Psychol Med 45, 1509-1519.

[44] Ritchie K, Ropacki M, Albala B, Harrison J, Kaye J, Kramer J, Randolph C, Ritchie CW (2017) Recommended cognitive outcomes in preclinical Alzheimer's disease: Consensus statement from the European Prevention of Alzheimer's Dementia project. Alzheimers Dement 13, 186-195.

[45] Amariglio RE, Becker JA, Carmasin J, Wadsworth LP, Lorius N, Sullivan C, Maye JE, Gidicsin C, Pepin L (2012) Subjective cognitive complaints and amyloid burden in cognitively normal older individuals. Neuropsychologia 50, 2880-2886.

[46] Eckerström M, Göthlin M, Rolstad S, Hessen E, Eckerström C, Nordlund A, Johansson B, Svensson J, Jonsson M, Sacuiu S, Wallin A (2017) Longitudinal evaluation of criteria for subjective cognitive decline and preclinical Alzheimer's disease in a memory clinic sample. Alzheimers Dement (Amst) 8, 96-107.

[47] Harvey PD, Twamley EW, Pinkham AE, Depp CA, Patterson TL (2017) Depression in schizophrenia: Associations with cognition, functional capacity, everyday functioning, and self-assessment. Schizophr Bull 43, 575-582.

[48] Beck A, Rush J, Shaw B, Emery G (1979) Cognitive therapy of depression. Guilford, New York.

[49] Crane MK, Bogner HR, Brown GK, Gallo JJ (2007) The link between depressive symptoms, negative cognitive bias and memory complaints in older adults. Aging Ment Health 11, 708-715.

[50] Schwert C, Stohrer M, Aschenbrenner S, Weisbrod M, Schroder A (2018) Biased neurocognitive self-perception in depressive and in healthy persons. $J$ Affect Disord 232, 96-102.

[51] Mulders PC, van Eijndhoven PF, Schene AH, Beckmann CF, Tendolkar I (2015) Resting-state functional connectivity in major depressive disorder: A review. Neurosci Biobehav Rev 56, 330-344.
[52] Kohler S, van Boxtel M, Jolles J, Verhey F (2011) Depressive symptoms and risk for dementia: A 9-year follow-up of the Maastricht Aging Study. Am J Geriatr Psychiatry 19, 902-905.

[53] American Psychiatric Association (2013) Diagnostic and statistical manual of mental disorders (5thed.). Washington, DC.

[54] Amieva H, Le Goff M, Millet X, Orgogozo JM, Peres K, Barberger-Gateau P, Jacqmin-Gadda H, Dartigues JF (2008) Prodromal Alzheimer's disease: Successive emergence of the clinical symptoms. Ann Neurol 64, 492-498.

[55] Knapskog A-B, Barca ML, Engedal K (2014) Prevalence of depression among memory clinic patients as measured by the Cornell Scale of Depression in Dementia. Aging Ment Health 18, 579-587.

[56] Yim SJ, Yi D, Byun MS, Choe YM, Choi HJ, Baek H, Sohn BK, Kim JW, Kim EJ, Lee DY (2017) Screening ability of subjective memory complaints, informant-reports for cognitive decline, and their combination in memory clinic setting. Psychiatry Investig 14, 640-646.

[57] Li M, Harris I, Lu ZK (2015) Differences in proxy-reported and patient-reported outcomes: Assessing health and functional status among medicare beneficiaries. BMC Med Res Methodol 15, 62.

[58] Schwartz CE, Ayandeh A, Rodgers JD, Duberstein P, Weinstock-Guttman B, Benedict RH (2015) A new perspective on proxy report: Investigating implicit processes of understanding through patient-proxy congruence. Qual Life Res 24, 2637-2649.

[59] Reid LM, Maclullich AM (2006) Subjective memory complaints and cognitive impairment in older people. Dement Geriatr Cogn Dis 22, 471-485.

[60] Moerbeek M, van Breukelen GJ, Berger MP (2003) A comparison between traditional methods and multilevel regression for the analysis of multicenter intervention studies. J Clin Epidemiol 56, 341-350.

[61] de Vugt ME, Verhey FR (2013) The impact of early dementia diagnosis and intervention on informal caregivers. Prog Neurobiol 110, 54-62.

[62] Joosten-Weyn Banningh LW, Kessels RP, Olde Rikkert MG, Geleijns-Lanting CE, Kraaimaat FW (2008) A cognitive behavioural group therapy for patients diagnosed with mild cognitive impairment and their significant others: Feasibility and preliminary results. Clin Rehabil 22, 731-740.

[63] Banningh LW, Vernooij-Dassen MJ, Vullings M, Prins JB, Rikkert MG, Kessels RP (2013) Learning to live with a loved one with mild cognitive impairment: Effectiveness of a waiting list controlled trial of a group intervention on significant others' sense of competence and well-being. Am J Alzheimers Dis Other Demen 28, 228-238. 